\title{
Efecto de levaduras de origen marino y ulvan en el control poscosecha de Penicillium italicum agente causal del moho azul en limón persa
}

\author{
Effect of marine yeasts and ulvan on the postharvest control of Penicillium italicum causal agent \\ of blue mold in Persian lemon
}

\begin{abstract}
María Luisa Vázquez-Vázquez', Roberto Gregorio Chiquito-Contreras', Gabriela Sanchez-Viveros', Juan José ReyesPérez ${ }^{2}$, María de Jesús Martinez-Hernandez ${ }^{1}$, Luis Guillermo Hernandez-Montiel ${ }^{3 *}$

Facultad de Ciencias Agrícolas. Campus Xalapa. Universidad Veracruzana. Circuito Universitario Gonzalo Aguirre Beltrán S/N. Zona Universitaria. 91090. Xalapa, Veracruz, México.

2 Universidad Técnica Estatal de Quevedo. Av. Quito. km 1.5. Vía a Santo Domingo. Quevedo, Los Ríos, Ecuador.

3 Centro de Investigaciones Biológicas del Noroeste. Av. Instituto Politécnico Nacional 195. Col. Playa Palo de Santa Rita Sur. 23096. La Paz, Baja California Sur, México.
\end{abstract}

\section{RESUMEN}

Penicillium italicum es un hongo que causa el moho azul en los cítricos. Su control es con fungicidas sintéticos, sin embargo, levaduras de origen marino y ulvan son una alternativa a los agro-productos sintéticos. El objetivo del estudio fue determinar el antagonismo in vitro de levaduras hacia $P$. italicum y su efecto con ulvan en el control del moho azul en frutos de limón persa. Se evaluó el efecto de ulvan sobre $P$. italicum y levaduras, para esto se determinó el antagonismo in vitro por confrontación entre levadura-fitopatógeno y competencia por carbohidratos. Se evaluó la protección de frutos con levaduras y ulvan hacia $P$. italicum y se determinó severidad e incidencia de la enfermedad y expresión de SOD, POX y CAT. No hubo efecto de ulvan sobre los microorganismos. In vitro las levaduras inhibieron al fitopatógeno. Los carbohidratos disminuyeron con levaduras y $P$. italicum y se inhibió la germinación de esporas del fitopatógeno. La incidencia de $P$. italicum en los frutos fue disminuida por levaduras y ulvan. POX, CAT y SOD se incrementó en los frutos con levaduras y ulvan. La aplicación de levaduras de origen marino más ulvan puede ser una opción en el control del moho azul en frutos de limón persa.

Palabras clave: Mecanismos antagónicos; control biológico; frutos; enzimas de defensa.

\section{ABSTRACT}

Penicillium italicum is a fungus that cause the blue mold on citrus fruits. Its control is with synthetic fungicides, however, marine yeasts and ulvan are an alternative to synthetic agro-products. The objective of this study was to determine in vitro antagonism of yeasts against $P$. italicum and its effect with ulvan in the control of blue mold in Persian lemon fruits. The effect of ulvan on $P$. italicum and yeasts was evaluated, for this in vitro antagonism was determined by confrontation between yeast-phytopathogen and competition for carbohydrates. The protection of fruits with yeasts and ulvan against $P$. italicum was evaluated and the severity and incidence of the disease and the expression of SOD, POX and CAT were determined. There was no effect of ulvan on microorganisms. In vitro, yeasts inhibited the phytopatho- gen. Carbohydrates decreased with yeast and $P$. italicum, and spore germination of the phytopathogen was inhibited. The incidence of $P$. italicum in the fruits was decreased by yeast and ulvan. POX, CAT and SOD increased in fruits with yeast and ulvan. The application of marine yeasts and ulvan may be an option for the control of blue mold in Persian lemon fruits.

Keyword: Antagonistic mechanisms; biological control; fruit; defense enzymes.

\section{INTRODUCCIÓN}

El limón persa (Citrus latifolia Tanaka), es un cítrico comercializado por su alto contenido de vitamina $\mathrm{C} y$ aceites esenciales (Pérez-Nájera et al., 2013; Fathollahi et al., 2021). México ocupa el primer lugar a nivel mundial en la producción de limón (FAO, 2019). Sin embargo, existen pérdidas en poscosecha cercana al $50 \%$ de la producción debido a hongos fitopatógenos. El hongo Penicillium italicum, es el agente causal del moho azul en los cítricos, afectado drásticamente la calidad del fruto y vida de anaquel (Jing et al., 2020). Los fungicidas sintéticos son los productos más utilizados convencionalmente para el control de $P$. italicum en poscosecha de cítricos (Chen et al., 2020). Sin embargo, han resultado ser ineficientes debido a que favorecen el desarrollo de fitopatógenos resistentes, además de presentar efectos negativos a la salud humana, animal y ambiental (Leyva-Acuña et al., 2020; Ons et al., 2020).

En la actualidad, la aplicación de microorganismos antagónicos como agentes de control biológico hacia fitopatógenos es una alternativa al uso de agro-productos sintéticos (Sui et al., 2020; Cerna-Chávez et al., 2021; Sánchez-Espinosa et al., 2021). Las levaduras aisladas de planta, suelo o fruto han sido eficientes en el control de enfermedades en poscosecha, sin embargo, existen levaduras aisladas de ambientes marinos, las cuales, han demostrado tener mayor capacidad antagónica que las aisladas de ambientes terrestres e incluso de fungicidas sintéticos (Rivas-Garcia et al., 2018). Dentro de los mecanismos antagónicos de levaduras hacia los fitopatógenos están; competencia por espacio y nutrimentos, producción de enzimas hidrolíticas, compuestos orgánicos

*Autor para correspondencia: Luis Guillermo Hernández Montiel Correo electrónico: Ihernandez@cibnor.mx 
volátiles, inducción de resistencia en el hospedero, entre otros (Mukherjee et al., 2020). Generalmente, se determina la capacidad antagónica de una levadura sobre frutos infectados por un fitopatógeno, sin embargo, en la actualidad, los consorcios microbianos han mostrado una mayor capacidad de inhibición debido a que se potencializan sus mecanismos de acción, además de incrementar su adaptación al hospedero (Palmieri et al., 2017).

Por otra parte, el alga verde marina Ulva sp. por la actividad de sus polisacáridos ha sido estudiada como antioxidante, antibacteriano, larvicida, anticoagulante, promotora del crecimiento vegetal, inductor de resistencia en el hospedero, entre otros (Li et al., 2020). El polisacárido ulvan protege a las plantas debido a su capacidad de inducir la resistencia sistémica adquirida, aumentando diversos compuestos como peroxidasa, superóxido dismutasa, catalasa, proteínas relacionadas con la patogenia (PR), entre otros, las cuales, le confieren una mayor tolerancia al hospedero hacia la infección por fitopatógenos (Abouraicha et al., 2015).

La aplicación de microorganismos antagónicos más el polisacárido ulvan ha sido evaluado en el control de enfermedades en frutos (Rivas-Garcia et al., 2018; ChiquitoContreras et al., 2019), sin embargo, el efecto de levaduras de origen marino y ulvan no ha sido evaluado en el control de $P$. italicum en frutos de limón persa, lo cual, podría potenciar el control del moho azul, disminuyendo el uso de fungicidas sintéticos. Por lo anterior, en este estudio se determinó la capacidad antagónica in vitro de levaduras de origen marino hacia $P$. italicum y su efecto con ulvan en el control del moho azul sobre frutos de limón persa.

\section{MATERIALES Y MÉTODOS Levaduras de origen marino}

Las levaduras de origen marino fueron donadas por la colección de microorganismos perteneciente al CIBNOR y están identificadas como: Debaryomyces hansenii (cepa ECP4 y L1), Cryptococcus laurentii (cepa IRIICB) y Rhodotorula minuta (cepa IR4CF). Cada levadura se cultivó en medio Papa-Dextrosa-Agar (PDA, Difco ${ }^{\mathrm{TM}}$ ) a $25{ }^{\circ} \mathrm{C}$ por $48 \mathrm{~h}$. Posteriormente, se colectó la biomasa y con una solución salina $(0.85 \%)$ se ajustó su concentración a $1 \times 10^{6}$ células. $\mathrm{mL}^{-1}$ con ayuda de un hematocitómetro.

\section{Polisacárido ulvan}

Ulvan (\#ULV010, OligoTech', Elicityl Ltd., Crolles, Francia) se preparó a $2 \mathrm{mg} \cdot \mathrm{mL}^{-1}$ usando agua desionizada estéril.

\section{Muestreo}

Se colectaron frutos de limón persa de una empacadora del Municipio de Martínez de la Torre, Veracruz, México, con signos y síntomas de moho azul, y se etiquetaron para su posterior procesamiento.

\section{Aislamiento y patogenicidad de hongos poscosecha}

Se cortaron cuatro trozos del exocarpio (de $0.5 \mathrm{~cm}^{2}$ ) enfermo de cada fruto. Las muestras se lavaron con hipo- clorito de sodio al $5 \%$ por 3 min y después se hicieron dos lavados con agua destilada estéril. Los trozos se dejaron secar y se colocaron en placas con PDA más Bactrol al $0.05 \%$ y se incubaron a $28^{\circ} \mathrm{C}$ por 7 días. Los aislamientos fueron resembrados hasta obtener cultivos puros y se mantuvieron en placas con PDA y tubos inclinados a $4^{\circ} \mathrm{C}$.

Para la prueba de patogenicidad se usó la metodología de Navarta et al. (2014). Frutos de limón persa fueron sumergidos en hipoclorito de sodio al $5 \%$ por $3 \mathrm{~min}$, se enjuagaron en agua destilada estéril y secados en una campana de flujo laminar. Posteriormente, a cada fruto se le realizaron dos heridas de $2 \mathrm{~mm}$ con un bisturí estéril y se inoculo cada herida con un taquete $0.5 \mathrm{~cm}^{2}$ de diámetro proveniente de un cultivo en PDA de 7 días de cada aislamiento de Penicillium sp. Un grupo de frutos fue inoculado con agua destilada estéril como control. Los frutos se almacenaron a $27^{\circ} \mathrm{C}$ y $90 \%$ HR en recipientes de plástico estériles por 7 días. Se cuantificó diámetro de lesión $(\mathrm{mm})$ y la incidencia de la enfermedad (\%DI) (Saravanakumar et al., 2016), mediante la fórmula: \%DI $=\mathrm{Fl} / \mathrm{TF} \times 100$. Dónde: $\mathrm{Fl}$, es el número de frutos infectados y TF, es el total de frutos. Para confirmar los postulados de Koch cada hongo fue re-aislado de los frutos en placas con PDA. Se utilizaron 10 frutos por tratamiento y el experimento se repitió dos veces.

\section{Identificación morfológica y molecular de hongos posco- secha}

Los hongos fitopatógenos fueron identificados a través de sus características morfológicas utilizando claves taxonómicas (Agrios, 2005) y por técnicas moleculares utilizando la región ITs1-5,8s-ITs-2 del ADN.

\section{Efecto de ulvan sobre el crecimiento de levaduras de origen marino y Penicillium italicum}

Fue seleccionada la cepa C2T de $P$. italicum por ser la más patogénica y se cultivó en placas con PDA a $25^{\circ} \mathrm{C}$ por 7 días. Las esporas se cosecharon en una solución salina al $0.85 \%$ con Tween 80 , ajustando su concentración a $1 \times 10^{4}$ esporas $\cdot \mathrm{mL}^{-1}$ con ayuda de un hematocitómetro (Tian et al., 2002).

\section{Efecto de ulvan sobre el crecimiento de levaduras de origen marino y $P$. italicum}

Matraces Erlenmeyer que contenían $50 \mathrm{~mL}$ de medio YPD se inocularon con $1 \mathrm{~mL}$ de la suspensión ajustada previamente de cada levadura y $2 \mu \mathrm{L}$ de ulvan. Los matraces se incubaron a $25^{\circ} \mathrm{C}$ y $125 \mathrm{rpm}$. Se recolectaron alícuotas de 10 $\mu \mathrm{L}$ a las $6,12,18,24$ y $30 \mathrm{~h}$ para determinar el crecimiento de las levaduras de origen marino, con y sin, ulvan utilizando un espectrofotómetro UV a una longitud de onda de $620 \mathrm{~nm}$. Se realizaron lecturas por triplicado por tratamiento en cada intervalo de tiempo y el experimento se repitió dos veces.

Para $P$. italicum, matraces Erlenmeyer que contenían $50 \mathrm{~mL}$ de medio de cultivo Caldo Papa y Dextrosa (Difco, Detroit, USA), se inocularon con $1 \mathrm{~mL}$ de la suspensión ajustada previamente del hongo y $2 \mu \mathrm{L}$ de ulvan. Los matraces se 
incubaron a $25^{\circ} \mathrm{C}$ y $125 \mathrm{rpm}$. Se colectaron alícuotas de $10 \mu \mathrm{L}$ cada $6,12,18$ y 24 h, colocándolas en un portaobjetos para ser observadas en un microscopio óptico. Se determinó la germinación de esporas, contabilizando 100 esporas y considerando una espora germinada, cuando el tubo germinativo fue igual o mayor al tamaño de la espora. Se realizaron tres repeticiones por tratamiento y el experimento se repitió dos veces.

\section{Antagonismo in vitro de levaduras de origen marino hacia P. italicum}

Los ensayos de confrontación antagonista-fitopatógeno se llevaron a cabo en placas con PDA. Se estrío una línea de $4 \mathrm{~cm}$ de cada levadura y la combinación de ellas en el centro de la placa, posteriormente a $2 \mathrm{~cm}$ de distancia se colocó una alícuota de $20 \mu \mathrm{L}$ de la suspensión ajustada del fitopatógeno $\left(1 \times 10^{4}\right.$ esporas $\left.\cdot \mathrm{mL}^{-1}\right)$. Un grupo de placas se inoculó con el fitopatógeno y $30 \mu \mathrm{L}$ de un fungicida sintético (Benomyl 50 , a una concentración de 1000 ppm) y otro grupo solo fue inoculado con P. italicum (tratamiento control). Las placas fueron incubadas a $25^{\circ} \mathrm{C}$ por 7 días. Se cuantificó el diámetro de crecimiento $(\mathrm{mm})$ del fitopatógeno y se calculó la reducción del crecimiento micelial con la fórmula I (\%) $=\mathrm{DC}-\mathrm{DT} / \mathrm{DC} \times 100$. Dónde: $\mathrm{DC}$, es el micelio cuantificado en el tratamiento control y DT, es el diámetro del hongo en el tratamiento con levaduras de origen marino. Se realizaron tres repeticiones por tratamiento y el experimento se repitió dos veces.

\section{Competencia in vitro por nutrimentos entre levaduras de origen marino y $P$. italicum \\ Medio de cultivo a base de flavedo de limón persa}

El medio de cultivo se elaboró utilizando frutos de limón persa previamente lavados con agua del grifo, agua destilada y pelados con un bisturí estéril. Para preparar el medio a base de limón se utilizó $47.6 \mathrm{~g}$ de flavedo que se depositó en un matraz de $1 \mathrm{~L}$ con $680 \mathrm{~mL}$ de agua destilada. Se esterilizó el medio a $120^{\circ} \mathrm{C}$ por $15 \mathrm{~min}$ y se vació $10 \mathrm{~mL}$ del sobrenadante en tubos falcón.

\section{Desarrollo experimental}

En cada tubo falcón, se depositaron $800 \mu \mathrm{L}$ de la suspensión ajustada previamente de cada levadura y cuando fue en combinacion se depositaron $200 \mu \mathrm{L}$ de cada levadura más $800 \mu \mathrm{L}$ de la suspensión ajustada previamente de $P$. italicum. Los tubos falcón se incubaron a $25^{\circ} \mathrm{C}$ y $150 \mathrm{rpm}$ por $24 \mathrm{~h}$. Se tomaron alícuotas de $3 \mathrm{~mL}$ para determinar; carbohidratos totales, sacarosa, glucosa y fructosa, y de 1 $\mathrm{mL}$ para determinar el número de esporas germinadas del hongo. Se consideró a una espora germinada cuando el tubo de germinación era igual o mayor al tamaño de la espora. Se observaron 100 esporas por tratamiento y se realizaron tres repeticiones. El experimento se repitió dos veces.

\section{Determinación de carbohidratos}

Para la determinación del contenido de glucosa se utilizó el método GOD-PAD de Barham y Trinder (1972), utili- zando el kit Randox (Randox México S.A. de C.V). Se mezclaron $5 \mathrm{~mL}$ de la muestra con $50 \mathrm{~mL}$ de la solución reactiva. Después de incubar 30 min se midió la absorbancia en espectrofotómetro a $490 \mathrm{~nm}$. Los valores se expresaron en $\mathrm{mg} \cdot \mathrm{mL}^{-1}$. La fructosa se cuantificó por el método de Taylor (1995). Se adicionaron $5 \mathrm{~mL}$ de muestra, $20 \mathrm{~mL}$ triptamida- $\mathrm{HCl}$ y 600 $\mathrm{mL}$ de $\mathrm{HCl}$ concentrado. Los tubos se mezclaron y calentaron a $60{ }^{\circ} \mathrm{C}$ en baño maría por $15 \mathrm{~min}$ y se enfriaron en agua por $40 \mathrm{~min}$. Finalmente, se midió en un espectrofotómetro la absorbancia a $518 \mathrm{~nm}$. Las concentraciones se obtienen interpolando las absorbancias obtenidas con una curva de calibración de fructosa y sus valores se expresaron en $\mathrm{mg} / \mathrm{mL}$. La sacarosa se cuantificó con el método de Bruner (1964). Se mezclaron $2 \mathrm{~mL}$ de muestra y $4 \mathrm{~mL}$ de $\mathrm{HCl} 3 \mathrm{M}$, posteriormente se calentó a $100^{\circ} \mathrm{C}$ en baño maría por $15 \mathrm{~min}$. Para neutralizar se añadieron $10 \mathrm{~mL}$ de $\mathrm{KOH} 5 \mathrm{~N}$ y $600 \mathrm{~mL}$ de DNS (3,5-Dinitro ácido salicílico). La mezcla se calentó a 100 ${ }^{\circ} \mathrm{C}$ por 10 min en baño maría y se enfrió en agua con hielo. Se midió la absorbancia en un espectrofotómetro a $570 \mathrm{~nm}$. El resultado se interpoló con una curva de calibración y los valores se expresaron en $\mathrm{mg} \cdot \mathrm{mL}^{-1}$.

\section{Antagonismo in vivo de levaduras de origen marino en frutos de limón persa con $P$. italicum y ulvan}

Frutos de limón se lavaron con agua destilada estéril y desinfectados con hipoclorito de sodio al $5 \%$ por $1 \mathrm{~min}$ (Yao et al., 2004). Se enjuagaron en agua destilada estéril y se dejaron secar por $1 \mathrm{~h}$ en una campana de flujo laminar. Posteriormente, a cada fruto se le realizaron dos heridas de $2 \mathrm{~mm}$ de profundidad con una aguja estéril y en cada una se inocularon $20 \mu \mathrm{L}$ de la suspensión ajustada previamente del fitopatógeno. Después, cada herida fue inoculada de manera individual o combinada con $20 \mu \mathrm{L}$ de la suspensión ajustada previamente de cada levadura y ulvan. Un grupo de frutos fueron inoculados con el fitopatógeno más $15 \mu \mathrm{L}$ del fungicida sintético Benomyl $50^{\circ}$. Otro grupo fue inoculado con el fitopatógeno y ulvan y un grupo control solo con P. italicum.

Los frutos se colocaron en recipientes de plástico estériles a $25^{\circ} \mathrm{C}$ y $90 \%$ HR por 7 días. Se cuantificó diámetro de lesión $(\mathrm{mm})$ y la incidencia de la enfermedad (\%DI) (Saravanakumar et al., 2016) mediante la fórmula: $\% \mathrm{DI}=\mathrm{FI} / \mathrm{TF} \times$ 100. Dónde: $\mathrm{Fl}$, es el número de frutos infectados y TF, es el total de frutos. Para confirmar los postulados de Koch se reaisló cada hongo de los frutos enfermos en placas con PDA. Se utilizaron cinco frutos por tratamiento y el experimento se repitió dos veces.

\section{Inducción de resistencia en frutos de limón persa inocu- lados con levaduras de origen marino, $P$. italicum y ulvan Muestra}

Para determinar la inducción de resistencia de frutos de limón persa inoculados con levaduras de origen marino, $P$. italicum y ulvan se cuantificó la actividad enzimática en los frutos a las $24 \mathrm{~h}$ después de la inoculación de cada tratamiento. Se hizo una mezcla compuesta de cada tratamiento colectado ( $1 \mathrm{~g}$ de tejido) de cada fruto. Las muestras fueron almacenadas a $-40^{\circ} \mathrm{C}$ para su respectivo análisis. 


\section{Sobrenadante}

De la mezcla compuesta se pesó $0.1 \mathrm{~g}$ de tejido y se colocó en un tubo eppendorf, después se le agregaron $2 \mathrm{~mL}$ de buffer de fosfato y se colocaron en un homogeneizador durante $60 \mathrm{~s}$. Posteriormente, se centrifugaron a $10000 \times \mathrm{g}$ por $13 \mathrm{~min}$ a $5^{\circ} \mathrm{C}$. Transcurrido el tiempo, el sobrenadante se recuperó y se colocó en un tubo eppendorf y se almacenó a $-40^{\circ} \mathrm{C}$ para su posterior análisis. Se realizaron tres repeticiones por tratamiento.

\section{Actividad enzimática}

La actividad catalasa (CAT) se determinó en microplacas de 96 pozos, a cada uno se le agregaron $10 \mu \mathrm{L}$ de buffer de fosfato $100 \mathrm{nM}$ (pH 7.0), más $20 \mu \mathrm{L}$ del extracto y se incubaron por $6 \mathrm{~min}$. Transcurrido este tiempo se añadieron $20 \mu \mathrm{L}$ de peróxido de hidrógeno $8.82 \mathrm{M}$ y se les incubó por $20 \mathrm{~min}$ a temperatura ambiente. Posteriormente, se agregaron $30 \mu \mathrm{L}$ de hidróxido de potasio $(\mathrm{KOH}) 10 \mathrm{M}$, más $30 \mu \mathrm{L}$ de reactivo Purlpad $(23.5 \mathrm{M})$ y se les incubó por $10 \mathrm{~min}$. Por último, se añadieron $10 \mu \mathrm{L}$ de Peryodato de potasio $0.5 \mathrm{M}$ en $\mathrm{KOH} 0.5$ $M$, y se les volvió a incubar por 5 min. Finalmente, se hicieron lecturas a $540 \mathrm{~nm}$ en un espectrofotómetro. Para determinar la actividad de superóxido dismutasa (SOD), se utilizó una microplaca de 48 pozos, donde se colocaron $600 \mu \mathrm{L}$ de buffer de fosfato. Posteriormente, se les agregaron $20 \mu \mathrm{L}$ del extracto, se adicionaron $20 \mu \mathrm{L}$ de xantina oxidasa $y$, se agregaron otros $600 \mu \mathrm{L}$ de buffer de fosfato. Se hicieron lecturas a una absorbancia de $560 \mathrm{~nm}$, cada 30 s durante $5 \mathrm{~min}$. La actividad de peroxidasa (POX), se determinó en placas de 96 pozos colocando $10 \mu \mathrm{L}$ del extracto, después se les adicionaron 50 $\mu \mathrm{L}$ de solución de guaiacol y la muestra se cuantifico a 436 $\mathrm{nm}$ en un espectrofotómetro. Los valores fueron expresados en $\mathrm{U} / \mathrm{g}$ de proteína.

\section{Análisis estadístico}

Los datos se analizaron mediante análisis de varianza unidireccional (ANOVA) utilizando el software STATISTICA 10.0 (paquete de software StatSoft, Tulsa, OK) y se utilizó la prueba de Tukey $(P \leq 0.05)$ para la separación de medias. Antes del análisis de varianza, los porcentajes se transformaron en arcoseno-raíz cuadrada.

\section{RESULTADOS Y DISCUSIÓN}

\section{Aislamiento, identificación y patogenicidad de hongos aislados de frutos de limón persa}

Se aislaron siete hongos de frutos de limón persa identificados como Penicillium spp. En la prueba de patogenicidad, de los aislamientos catalogados como; CV2T, C2T, NFC, VFC, 2FC, CVMT y BFC, solo los primeros dos tuvieron una incidencia del $100 \%$ y el resto de los hongos no ocasionaron enfermedad sobre los frutos. El aislamiento C2T fue el que mayor daño ocasionó sobre los frutos con un diámetro de lesión de $49 \mathrm{~mm}$ seguido de CV2T con $39 \mathrm{~mm}$. Los hongos CV2T y C2T fueron re-aislados de los frutos confirmando los postulados de Koch. A través de la región ITs1-5,8s-ITs-2 del ADN, los siete hongos fueron identificados como Penicillium italicum mostrando una identidad del $100 \%$ según la base de datos del NCBI (National Center for Biotechnology Information, www.ncbi.nlm.nih.gov).

El limón ocupa dentro de los cítricos el segundo lugar en importancia, tanto por su consumo en fresco como por su uso industrial. Dentro del contexto mundial, México está considerado como el principal país productor en las variedades persa y mexicano (SADER, 2019). Después de la cosecha, el limón se almacena y manipula en plantas de embalaje con el fin de mantener su vida y calidad poscosecha, así como reducir la descomposición debido a la infección por fitopatógenos (Papoutsis et al., 2019). Sin embargo P. italicum, agente causal del moho azul, es uno de los principales hongos que causan pérdidas económicas de hasta el $80 \%$ de la producción de cítricos a nivel mundial (El-Otmani et al., 2011).

En México, P. italicum es uno de los principales fitopatógenos que causan pérdidas poscosecha cercanas al 50 $\%$ de la producción que incluye limón, naranja y mandarina (Ochoa et al., 2007). Debido a la gran cantidad de esporas que produce $P$. italicum, infecta rápidamente a las heridas de los frutos por lo que su control debe ser durante y después de la cosecha, para evitar grandes pérdidas de fruta (Kellerman et al., 2016). La rápida identificación de los fitopatógenos en poscosecha es fundamental para el manejo de las enfermedades en los cítricos limitando las pérdidas de fruta y manteniendo su calidad organoléptica (Kanashiro et al., 2020).

\section{Efecto de ulvan sobre $P$. italicum y levaduras de origen marino}

La presencia de ulvan no influyó sobre la germinación de esporas de $P$. italicum (Figura 1). En relación a las levaduras de origen marino, no existió un efecto de ulvan sobre el crecimiento de los microorganismos (Figura 2). La dinámica de crecimiento fue similar entre todos los tratamientos.

Las algas marinas han recibido una gran atención durante los últimos años, debido a la química natural de sus productos (Pankiewicz et al., 2016), principalmente a los polisacáridos que presentan diversas actividades biológicas como anticoagulantes, antivirales, antibacterianas, antitumorales, antiproliferativas, inmunomoduladoras, entre otras (Berri et al., 2016). Ulva sp. es un alga verde marina que está

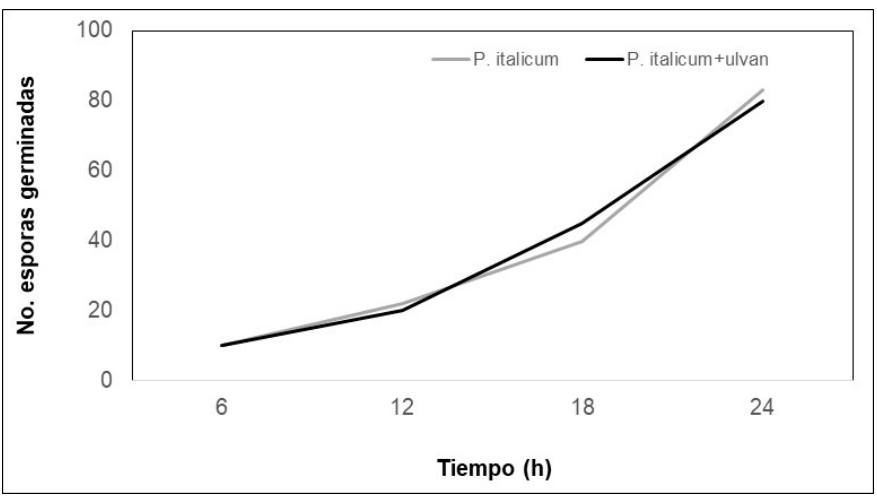

Figura 1. Dinámica de germinación de esporas de $P$. italicum con ulvan. Figure 1. Spore germination dynamics of $P$. italicum with ulvan. 

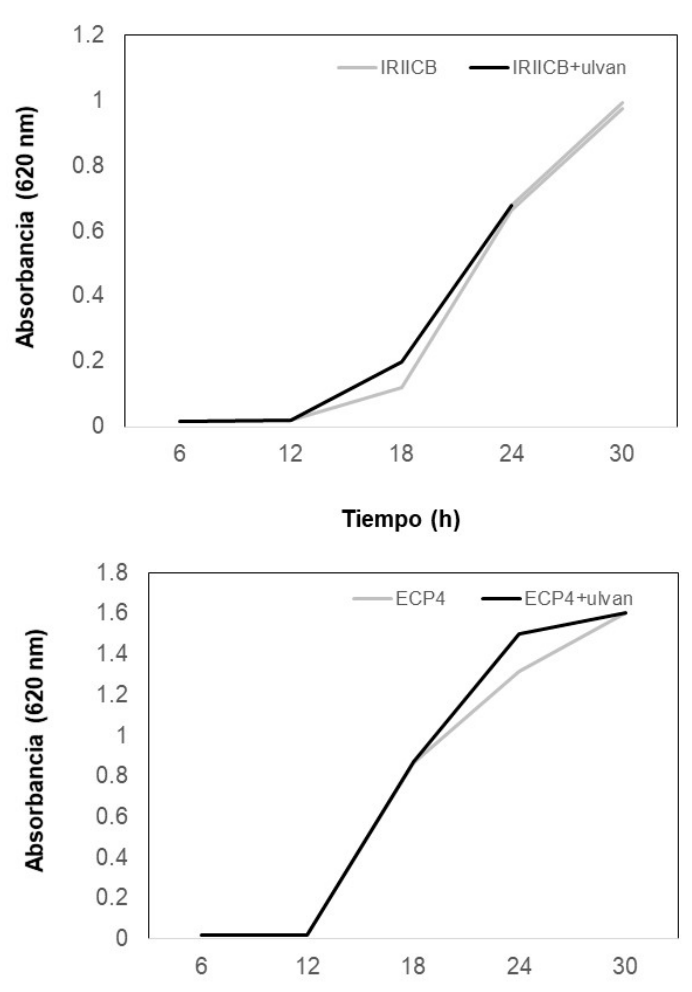

Tiempo (h)

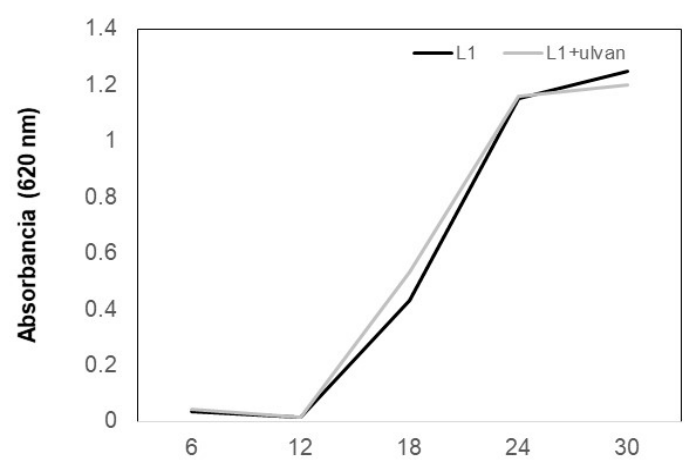

Tiempo (h)

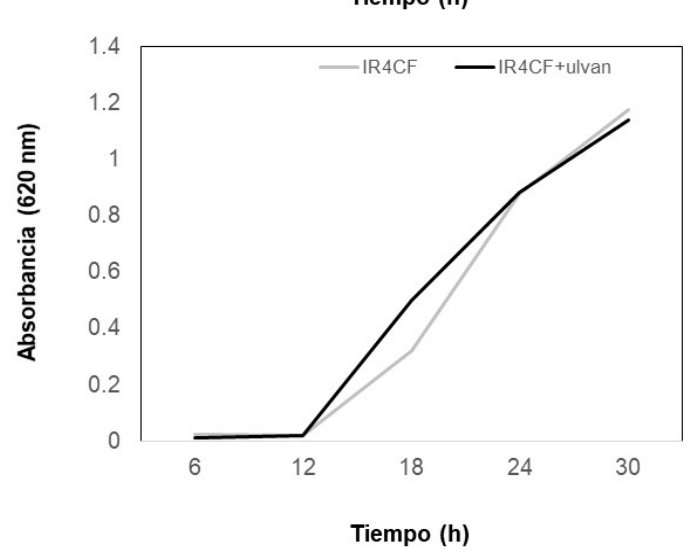

Figura 2. Dinámica de crecimiento de levaduras de origen marino con ulvan. $\mathrm{ECP} 4$ y $\mathrm{L} 1=D$. hansenii, IRIICB $=$ C. laurentii e IR4CF $=R$. minuta. Figure 2. Growth dynamics of marine yeasts with ulvan. ECP4 and $L 1=D$. hansenii, IRIICB $=C$. laurentii and IR4CF $=R$. minuta. recibiendo una gran atención, debido a sus propiedades fisicoquímicas y biológicas de posible interés para aplicaciones en diversas áreas como la cosmetología, medicina, agrícola, entre otras (Berri et al., 2016).

Ulvan es un polisacárido aislado de Ulva sp. que presenta actividad antiviral, antibacteriano, antioxidante, antiparasitario, entre otros (Chiquito-Contreras et al., 2019). En la agricultura, se ha utilizado como promotor del crecimiento vegetal e inductor de resistencia en las plantas, sin embargo, no presenta una acción antimicrobiana directa sobre los microorganismos (Rivas-Garcia et al., 2018). Su principal función en las plantas es inducir la producción de enzimas de defensa como la catalasa (CAT), peroxidasa (POX), polifenol oxidasa, superóxido dismutasa (SOD), compuestos fenólicos, proteínas relacionadas con la patogenia (PR), entre otros (Khedia et al., 2020; Moenne et al., 2020).

\section{Antagonismo in vitro de levaduras de origen marino hacia $P$. italicum}

Las levaduras de origen marino inhibieron el crecimiento micelial del fitopatógeno in vitro (Figura 3). La inhibición que ejercieron las levaduras de manera individual o en consorcio hacia $P$. italicum fue entre 21 y $38 \%$. El fungicida sintético Benomyl $50^{\circ}$ solo limito a $3 \%$ el crecimiento de $P$. italicum.

Existen diversos reportes sobre la capacidad antagónica de levaduras hacia fitopatógenos, Taqarort et al. (2008) evaluaron el biocontrol de $P$. digitatum mediante el uso de las levaduras Pichia anomala y D. hansenii. Por su parte, Zhang et al. (2007) y Droby et al. (2009) observaron una disminución del moho azul por la acción de la levadura Cryptococcus laurentii. Sin embargo, la acción antagónica de los microorganismos puede potenciarse si se utilizan consorcios microbianos, los cuales pueden tener un mayor espectro de actividad, por lo tanto, pueden reducir la presencia de los fitopatógenos eficazmente en comparación con su aplicación de manera individual (Palmieri et al., 2017). La eficiencia de los consorcios microbianos podría resultar no solo de la actividad de las especies individuales, sino también de su acción sinérgica que suprimirá el crecimiento de un fitopatógeno a través de diferentes mecanismos de acción (Panebianco et al., 2015). La aplicación de consorcios microbianos ha mejorado la eficiencia del control biológico de enfermedades en muchos sistemas agrícolas (Jain et al., 2020).

Por otra parte, el uso de fungicidas sintéticos sigue siendo la primera opción en el control de fitopatógenos de importancia agrícola (Zhu et al., 2020). Para el control de Penicillium sp. se recomienda el uso de diversos fungicidas sintéticos, entre ellos el Benomyl $50^{\circ}$, sin embargo, han perdido eficiencia en el control del fitopatógeno debido a la resistencia que presentan algunas cepas de diversas especies de Penicillium (Moussa et al., 2021).

\section{Competencia por carbohidratos entre levaduras de ori- gen marino y $P$. italicum}

El contenido de fructosa, glucosa y sacarosa disminuyó significativamente en presencia de levaduras de origen ma- 


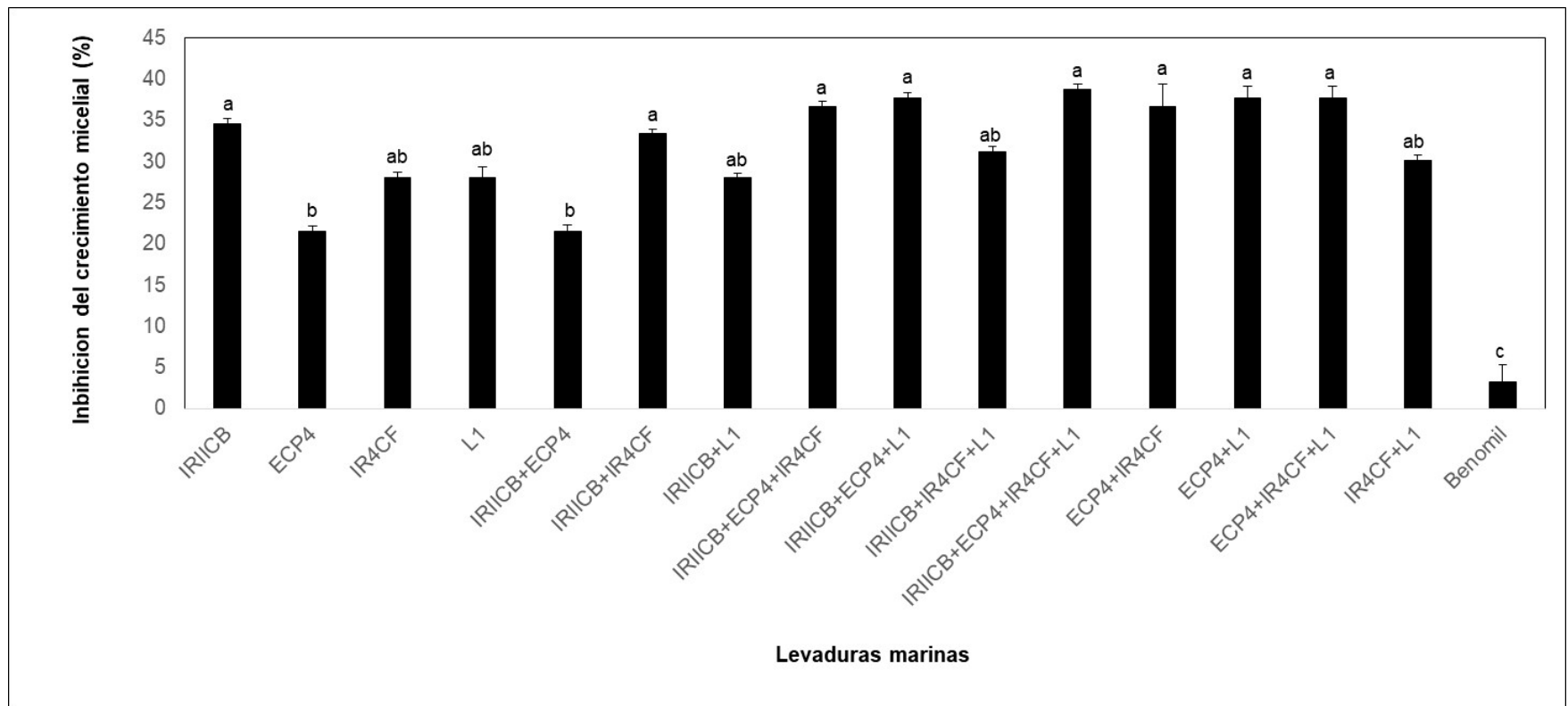

Figura 3. Efecto de la aplicación individual o en consorcio de levaduras de origen marino sobre el crecimiento micelial de P. italicum. ECP4 y L1 = D. hansenii, IRIICB $=$ C. laurentii e IR4CF $=R$. minuta. Las líneas verticales sobre las barras representan la desviación estándar $(\mathrm{n}=3)$. Las letras representan la diferencia estadística entre tratamientos (Tukey, $P \leq 0.05$ ).

Figure 3. Effect of the individual or consortium application of marine yeasts on the mycelial growth of $P$. italicum. ECP4 and L1 =D. hansenii, IRIICB $=C$. laurentii and IR4CF $=R$. minuta. Vertical lines on the bars represent the standard deviation $(\mathrm{n}=3)$. Letters represent the statistical difference between treatments (Tukey, $P \leq 0.05$ ).

rino y P. italicum (Figura 4). El consorcio con ECP4, L1, IRIICB y IR4CF más el fitopatógeno fue el que disminuyó significativamente el contenido de carbohidratos en el medio de cultivo a base de flavedo de limón persa (control). Por otra parte, las levaduras de origen marino inhibieron significativamente el número de esporas germinadas de $P$. italicum (Figura 5). EI consorcio conformado por ECP4, L1, IRIICB y IR4CF, inhibió en un $77 \%$ la germinación de esporas del fitopatógeno. $P$. italicum germino en un $89 \%$.
Todos los microorganismos requieren de azúcares como fuentes de carbono para su crecimiento y reproducción, la competencia por espacio y nutrientes es una vía antagónica de levaduras hacia fitopatógenos (Mukherjee et al., 2020), este mecanismo es eficaz debido a que las levaduras tienen un metabolismo más rápido que el fitopatógeno, agotando rápidamente las fuentes de carbono (fructosa, glucosa, sacarosa, entre otros) y limitando a la germinación de esporas (Spadaro y Droby, 2016; Adrees et al., 2019). Los

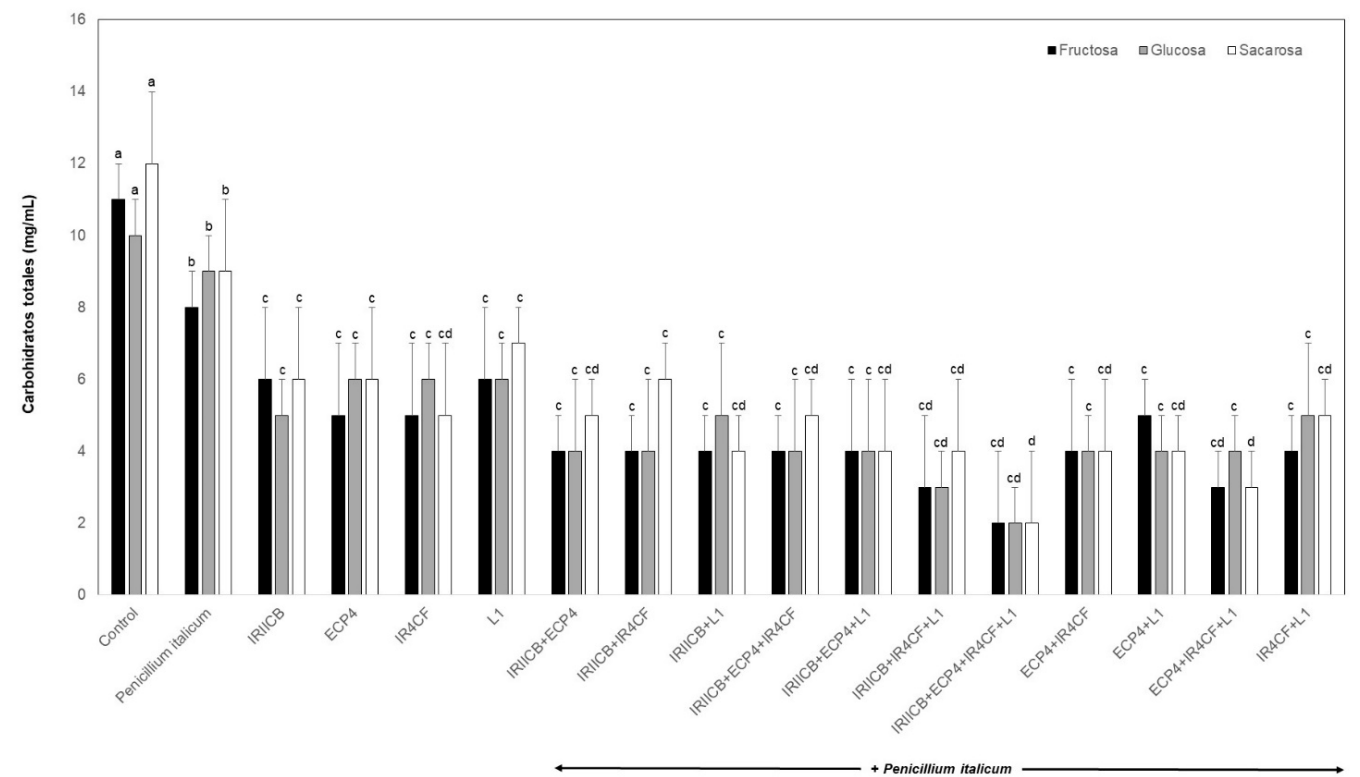

Figura 4. Contenido de carbohidratos en medio de cultivo a base de flavedo de limón persa inoculado con levaduras de origen marino y $P$. italicum. ECP4 y L1 = D. hansenii, IRIICB $=C$. laurentii e IR4CF $=R$. minuta . Las líneas verticales sobre las barras representan la desviación estándar $(\mathrm{n}=$ 3). Las letras representan la diferencia estadística entre tratamientos (Tukey, $P \leq 0.05$ ).

Figure 4. Carbohydrate content in culture medium based on Persian lemon flavedo inoculated with marine yeast and $P$. italicum. ECP4 and $\mathrm{L} 1=D$. hansenii, $\mathrm{IRIICB}=C$. laurentii and IR4CF $=R$. minuta. . Vertical lines on the bars represent the standard deviation $(n=3)$. Letters represent the statistical difference between treatments (Tukey, $P \leq 0.05$ ). 


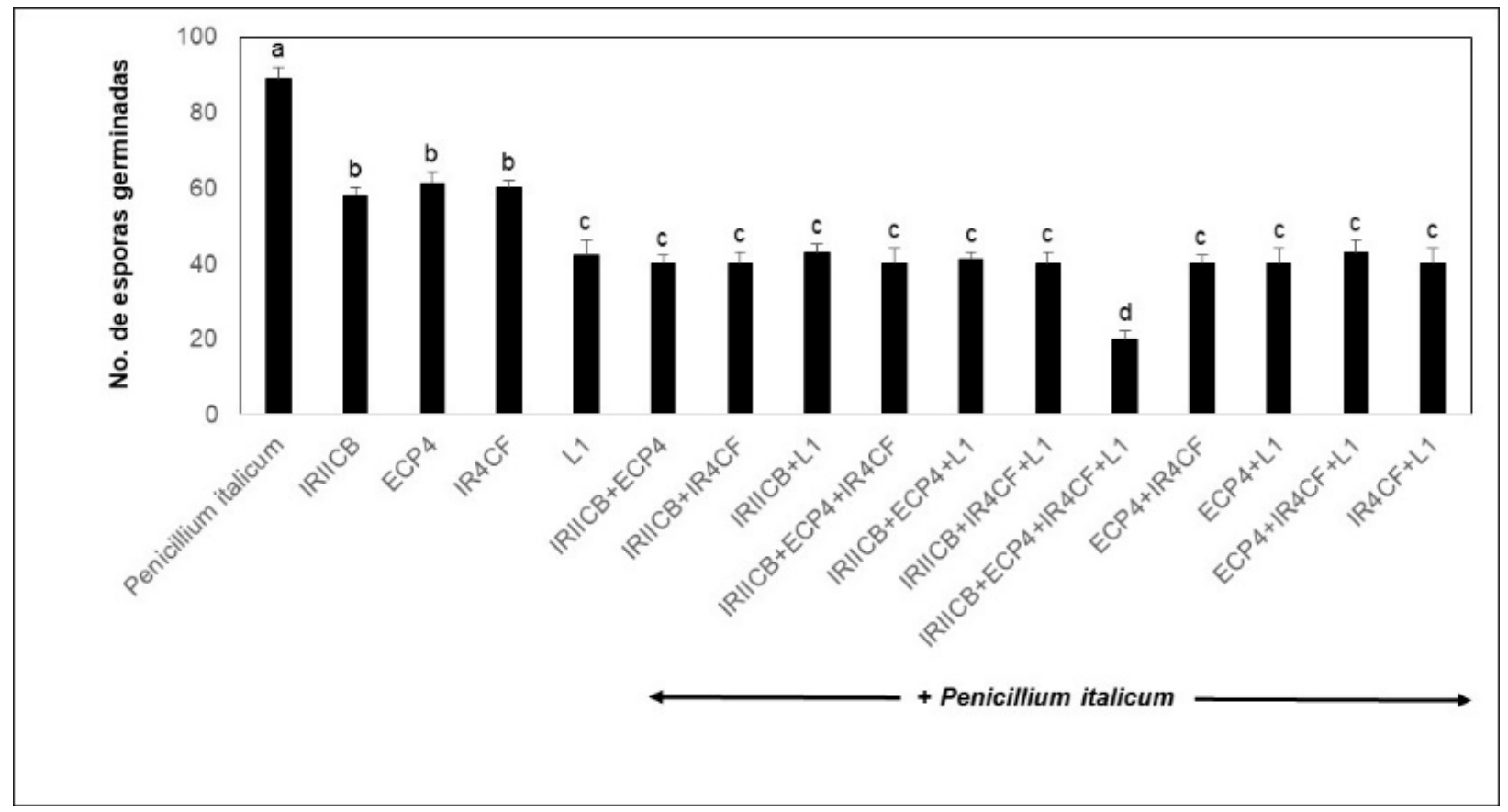

Figura 5. Germinación de esporas de $P$. italicum en medio de cultivo a base de flavedo de limón persa. ECP4 y L1 = D. hansenii, IRIICB $=C$. laurentii e IR4CF $=R$. minuta. Las líneas verticales sobre las barras representan la desviación estándar $(n=3)$. Las letras representan la diferencia estadística entre tratamientos (Tukey, $P \leq 0.05$ ).

Figure 5. Spore germination of $P$. italicum in a Persian lemon flavedo-based culture medium. $\mathrm{ECP} 4$ and $\mathrm{L} 1=D$. hansenii, IRIICB $=C$. laurentii and IR4CF $=R$. minuta. Vertical lines on the bars represent the standard deviation $(n=3)$. Letters represent the statistical difference between treatments (Tukey, $P \leq 0.05$ ).

microorganismos antagonistas deben tener la capacidad de competir efectivamente por los nutrientes disponibles en el nicho ecológico para colonizar y limitar el crecimiento de los fitopatógenos. Al respeto, Spadaro et al. (2010), mencionan que los microrganismos antagonistas tienen la capacidad de asimilar una amplia variedad de mono y disacáridos. Hernández-Montiel et al. (2010), reportaron que las levaduras presentan una mayor tasa de consumo de glucosa y sacarosa que los fitopatógenos, lo cual restringe la germinación de la espora de los hongos.

\section{Efecto levaduras de origen marino y ulvan en el control de $P$. italicum en frutos de limón persa}

La incidencia de $P$. italicum en frutos de limón persa fue disminuida por la inoculación de levaduras de origen marino, ulvan y el fungicida sintético (Figura 6). La aplicación del consorcio microbiano con las cepas ECP4, L1, IRIICB y IR4CF disminuyó la incidencia de la enfermedad hasta en un $20 \%$ y los frutos de limón persa con Benomyl $50^{\circledR}$ más $P$. italicum presentaron un $60 \%$ de incidencia. En relación al diámetro de lesión, las levaduras de origen marino, ulvan y Benomyl $50^{\circ}$ disminuyeron significativamente el daño ocasionado por el fitopatógeno en frutos de limón persa (Figura 7). Los frutos inoculados con el consorcio conformado por ECP4, L1, IRIICB y IR4CF presentaron el diámetro de lesión más bajo con valores de $2 \mathrm{~mm}$. La aplicación de las levaduras de origen marino de manera individual o en consorcio disminuyó el diámetro de lesión en menos del $60 \%$ en comparación con el tratamiento de los frutos con Benomyl $50^{\circ}$ y el fitopatógeno.
P. italicum fue re-aislado de los frutos enfermos confirmando los postulados de Koch.

La actividad enzimática de POX, CAT y SOD fue incrementada en los frutos de limón persa inoculados con levaduras de origen marino y ulvan (Tabla 1). Los valores más altos de las enzimas fueron cuantificados en el tratamiento de los frutos con el fitopatógeno más las levaduras y ulvan.

Diversos mecanismos antagónicos por levaduras están relacionados con el control biológico de enfermedades en los frutos (Wassermann et al., 2019), incluyendo la competencia por nutrientes y espacio, toxinas killer, producción de enzimas hidrolíticas, parasitismo, bio-películas, compuestos orgánicos volátiles, inducción de resistencia del hospedero, entre otros (Konsue et al., 2020; Solairaj et al., 2020). La protección de los frutos puede ser incrementada cuando se aplican más de dos microorganismos antagónicos compatibles (Zhimo et al., 2020), los cuales presentan varias ventajas sobre el uso de una sola especie, incluida una mayor eficacia de biocontrol de los fitopatógenos, resistencia al estrés ambiental y rápida adaptación al hospedero (Pandhal y Noirel, 2014; Mukherjee et al., 2020).

Por otra parte, levaduras de origen marino y ulvan son capaces de activar la producción de enzimas SOD, CAT y POX en diversos hospederos disminuyendo las infecciones ocasionadas por diversos fitopatógenos (Khedia et al., 2020; Zhang et al., 2020). Las enzimas de defensa protegen a los frutos de diversas especias reactivas de oxígeno (ROS) causadas por fitopatógenos (Czarnecka et al., 2019). Las ROS originan daños directamente sobre las células vegetales afectando 


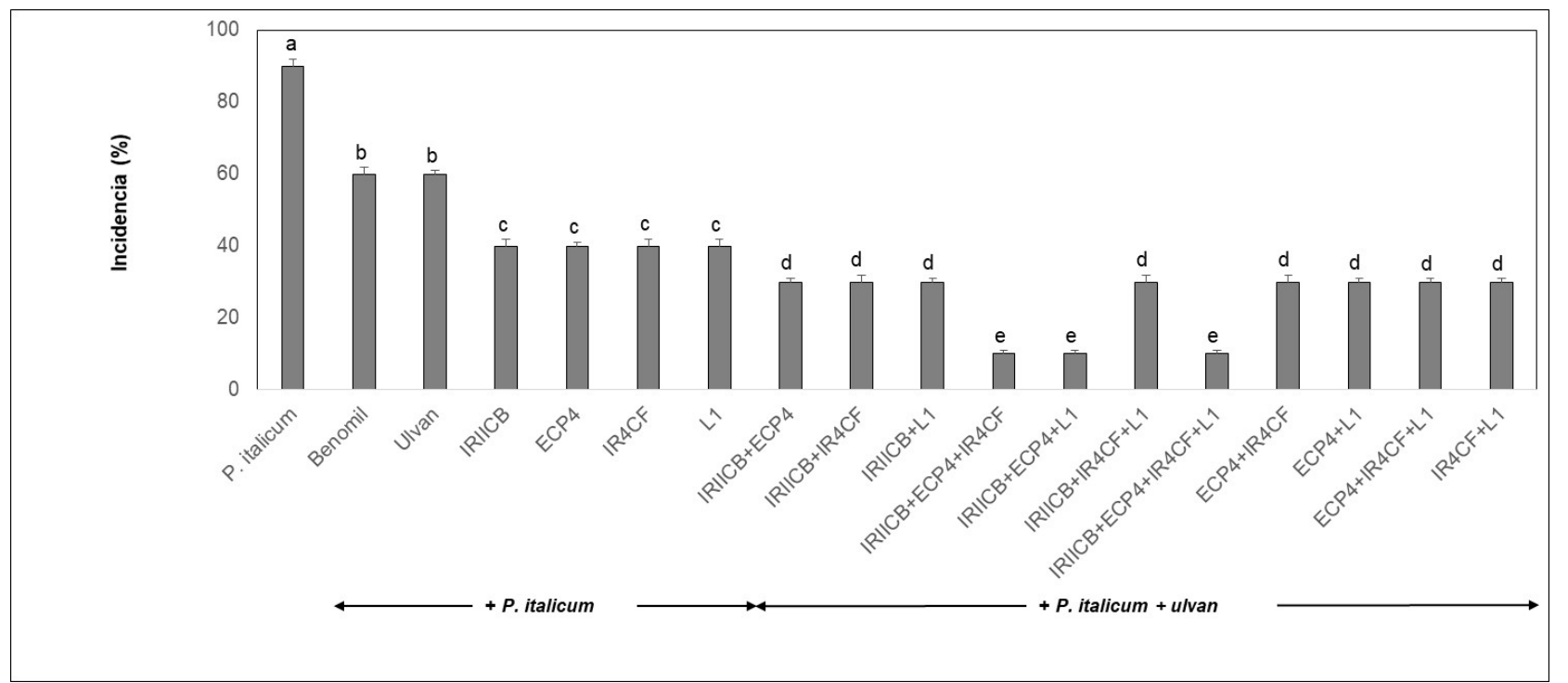

Figura 6. Incidencia de $P$. italicum en frutos de limón persa inoculados con levaduras de origen marino y ulvan. ECP4 y L1 = D. hansenii, IRIICB $=$ C. laurentii e IR4CF $=R$. minuta. Las líneas verticales sobre las barras representan la desviación estándar $(\mathrm{n}=5)$. Las letras representan la diferencia estadística entre tratamientos (Tukey, $P \leq 0.05$ ).

Figure 6. Incidence of $P$. italicum in Persian lemon fruits inoculated with marine yeasts and ulvan. ECP4 and L1 $=D$. hansenii, IRIICB $=C$. laurentii and IR4CF $=R$. minuta. Vertical lines on the bars represent the standard deviation $(n=5)$. Letters represent the statistical difference between treatments (Tukey, $P \leq 0.05$ ).

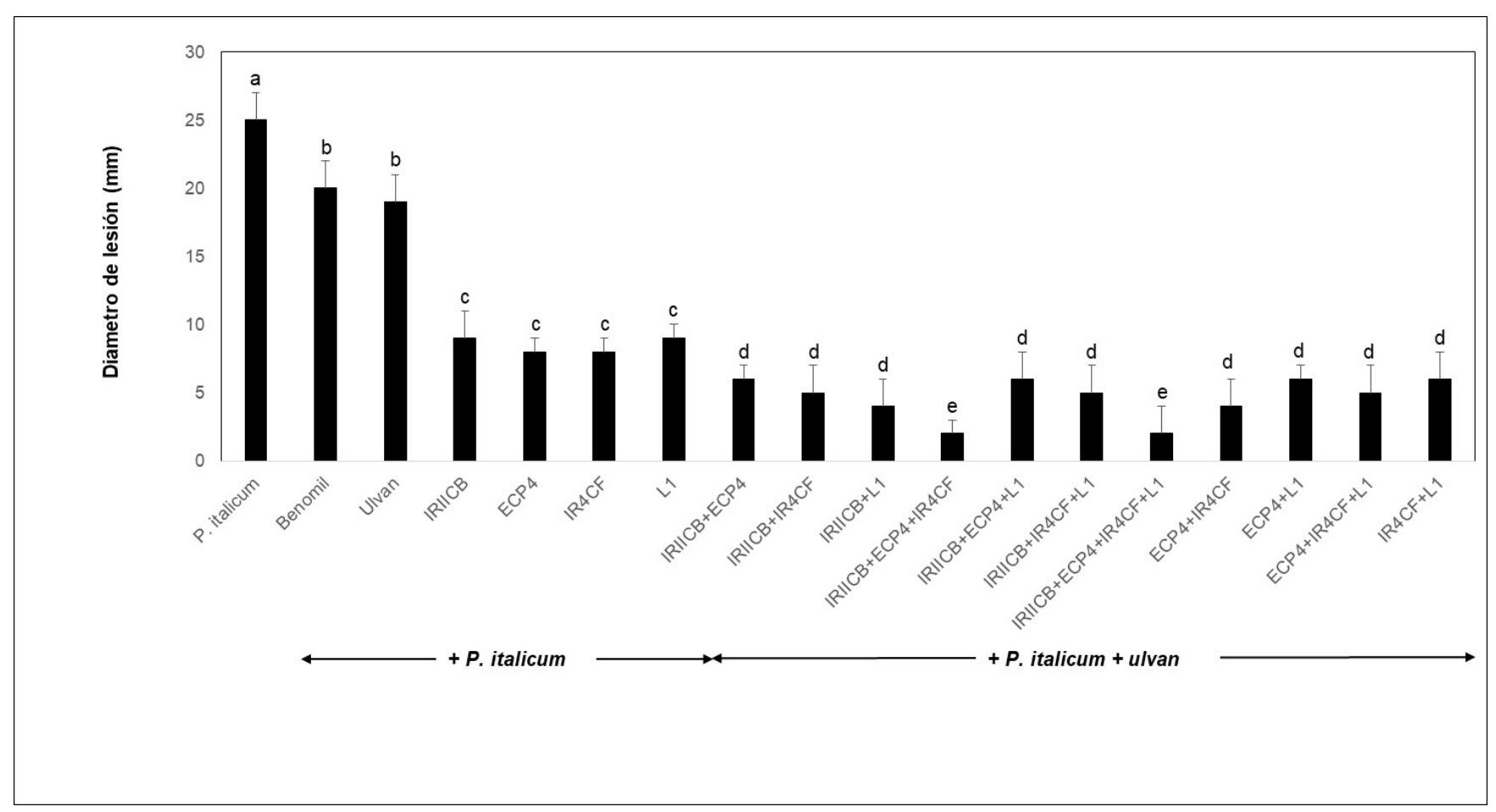

Figura 7. Diámetro de lesión ocasionado por $P$. italicum en frutos de limón persa inoculados con levaduras de origen marino y ulvan. ECP4 y L1 = $D$. hansenii, IRIICB $=C$. laurentii e IR4CF $=R$. minuta. Las líneas verticales sobre las barras representan la desviación estándar $(n=5)$. Las letras representan la diferencia estadística entre tratamientos (Tukey, $P \leq 0.05$ ).

Figure 7. Diameter of lesion caused by $P$. italicum in Persian lemon fruits inoculated with marine yeast and ulvan. $E C P 4$ and L1 $=D$. hansenii, IRIICB $=C$. laurentii and IR4CF $=R$. minuta. Vertical lines on the bars represent the standard deviation $(n=5)$. Letters represent the statistical difference between treatments (Tukey, $P \leq 0.05$ ). 
Tabla 1. Actividad enzimática de frutos de limón persa inoculados con levaduras de origen marino, ulvan y P. italicum.

Table 1. Enzymatic activity of Persian lemon fruits inoculated with marine yeasts, ulvan and $P$. italicum.

\begin{tabular}{|c|c|c|c|c|}
\hline & \multirow[t]{2}{*}{ Tratamiento $^{\varsigma}$} & \multicolumn{3}{|c|}{$\begin{array}{l}\text { Actividad enzimática } \\
\text { (U/g de proteína) }\end{array}$} \\
\hline & & POX $^{*}$ & CAT & SOD \\
\hline & P. italicum & $8.41 \pm 2 d^{£}$ & $7.98 \pm 1 \mathrm{~g}$ & $6.35 \pm 2 \mathrm{e}$ \\
\hline & Ulvan $+P$. italicum & $14.92 \pm 3 b$ & $10.28 \pm 2 \mathrm{e}$ & $8.19 \pm 1 \mathrm{~d}$ \\
\hline & IRIICB+P. italicum & $8.19 \pm 2 d$ & $7.78 \pm 2 \mathrm{~g}$ & $10.67 \pm 1 \mathrm{c}$ \\
\hline & ECP4+P. italicum & $7.91 \pm 1 \mathrm{~d}$ & $8.98 \pm 1 \mathrm{f}$ & $10.31 \pm 2 c$ \\
\hline & IR4CF+P. italicum & $7.33 \pm 1 \mathrm{~d}$ & $8.54 \pm 1 \mathrm{f}$ & $11.41 \pm 2 c$ \\
\hline & $\mathrm{L} 1+P$. italicum & $8.28 \pm 2 \mathrm{~d}$ & $5.47 \pm 3 h$ & $10.11 \pm 3 c$ \\
\hline \multirow{10}{*}{ 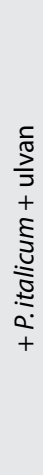 } & IRIICB+ECP4 & $11.21 \pm 2 b c$ & $12.64 \pm 3 \mathrm{~cd}$ & $13.21 \pm 3 b$ \\
\hline & IRIICB+IR4CF & $11.92 \pm 3 b c$ & $13.15 \pm 2 c$ & $13.48 \pm 3 b$ \\
\hline & IRIICB+L1 & $12.17 \pm 2 b c$ & $12.87 \pm 3 \mathrm{~cd}$ & $14.11 \pm 2 b$ \\
\hline & IRIICB+ECP4+IR4CF & $14.29 \pm 3 b$ & $15.68 \pm 1 b$ & $14.56 \pm 2 b$ \\
\hline & IRIICB+ECP4+L1 & $14.89 \pm 1 \mathrm{~b}$ & $16.47 \pm 1 \mathrm{~b}$ & $14.89 \pm 3 b$ \\
\hline & IRIICB+IR4CF+L1 & $15.27 \pm 1 b$ & $15.87 \pm 2 b$ & $15.13 \pm 2 b$ \\
\hline & IRIICB+ECP4+IR4CF+L1 & $19.97 \pm 3 \mathrm{a}$ & $20.45 \pm 3 a$ & $19.55 \pm 1 \mathrm{a}$ \\
\hline & ECP4+IR4CF & $12.19 \pm 2 b c$ & $12.35 \pm 2 c$ & $14.38 \pm 1 b$ \\
\hline & $\mathrm{ECP} 4+\mathrm{L} 1$ & $12.34 \pm 2 \mathrm{bc}$ & $13.01 \pm 1 \mathrm{c}$ & $13.98 \pm 2 b$ \\
\hline & ECP4+IR4CF+L1 & $11.97 \pm 1 b c$ & $13.22 \pm 1 c$ & $14.78 \pm 2 b$ \\
\hline
\end{tabular}

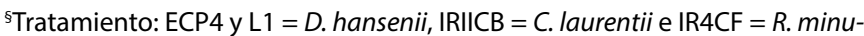
ta. ${ }^{¥}$ Actividad enzimática: POX (peroxidasa), CAT (catalasa), SOD (superóxido dismutasa). ${ }^{\complement}$ Las letras en las columnas representan la diferencia estadística entre tratamientos (Tukey, $P \leq 0.05$ ).

diversas funciones metabólicas de las plantas (Qi et al., 2019). La inducción de SOD en las plantas permite la reducción de las ROS en la célula, la POX y CAT disminuye y protege a las células vegetales de la actividad de $\mathrm{H}_{2} \mathrm{O}_{2}$ (Klein et al., 2018; Guo et al., 2020).

\section{CONCLUSIONES}

Las levaduras de origen marino ( $D$. hansenii, $R$. minuta y C. laurentii) inhibieron in vitro e in vivo a P. italicum. La aplicación de los consorcios de levaduras y ulvan sobre los frutos de limón persa disminuyó al moho azul ocasionado por $P$. italicum superando al fungicida sintético Benomyl $50^{\circ}$. La competencia por fuentes de carbono e inducción de resistencia del hospedero son dos mecanismos antagónicos de levaduras hacia fitopatógenos. La validación de consorcios a base de microrganismos antagónicos en empacadoras de limón persa permitirá la disminución del uso de fungicidas sintéticos.

\section{AGRADECIMIENTOS}

Al Consejo Nacional de Ciencia y Tecnología, por el financiamiento del proyecto 352/2015. M.L. Vázquez-Vázquez agradece al CONACYT por la beca otorgada para realizar sus estudios de posgrado a nivel maestría. R.G. Chiquito-Contreras y L.G. Hernandez-Montiel fueron codirectores de tesis.

\section{CONFLICTO DE INTERESES} de intereses.

Los autores de este trabajo no tienen ningún conflicto

\section{REFERENCIAS}

Abouraicha, E., El-Alaoui-Talibi, Z., El-Boutachfaiti, R., Petit, E., Courtois, B., Coutois, J. and El Modafar, C. 2015. Induction of natural defense and protection against Penicillium expansum and Botrytis cinerea in apple fruit in response to bioelicitors isolated from green algae. Scientia Horticulturea. 181: 121128.

Adrees, H., Haider, M., Anjum, T. and Akram, W. 2019. Inducing systemic resistance in cotton plants against charcoal root rot pathogen using indigenous rhizospheric bacterial strains and chemical elicitors. Crop Protection. 115: 75-83.

Berri, M., Slugocki, C., Oliver, M., Helloin, E., Jacques, I., Salmon, H., Demais, H., Le Goff, M. and Collen, P.N. 2016. Marinesulfated polysaccharides extract of Ulva armoricana green algae exhibits an antimicrobial activity and stimulates cytokine expression by intestinal epithelial cells. Journal of Applied Phycology. 28: 2999-3008.

Chen, C., Wan, C., Peng, X., and Chen, J. 2020. A flavonone pinocembroside inhibits Penicillium italicum growth and blue mold development in 'Newhall' navel oranges by targeting membrane damage mechanism. Pesticide Biochemistry and Physiology. 165: 104505.

Cerna-Chávez, E., De Lira-Ramos, K., Ochoa-Fuentes, Y., Delgado-Ortiz, J., Cepeda-Siller, M. y González-Gaona, E. 2021. Actividad de extractos de plantas y hongos entomopatógenos para el control del picudo de la guayaba (Conotrachelus dimidiatus Champion) Coleóptera: Curculionidae. Biotecnia. 23(1): 70-76.

Chiquito-Contreras, R., Murillo-Amador, B., Carmona-Hernandez, S., Chiquito-Contreras, C. and Hernandez-Montiel, L. 2019. Effect of marine bacteria and ulvan on the activity of antioxidant defense enzymes and the bio-protection of papaya fruit against Colletotrichum gloeosporioides. Antioxidants. 8(12): 580.

Collen, P. 2016. Marine sulfated polysaccharides extract of Ulva armoricana green algae exhibits an antimicrobial activity and stimulates cytokine expression by intestinal epithelial cell. Journal of Applied Phycology. 28: 2999-3008.

Czarnecka, M., Żarowska, B., Połomska, X., Restuccia, C. and Cirvilleri, G. 2019. Role of biocontrol yeasts Debaryomyces hansenii and Wickerhamomyces anomalus in plants defense mechanisms against Monilinia fructicola in apple fruits. Food Microbiology. 83: 1-8.

Droby, S., Wisniewski, M., Macarisin, D. and Wilson, C. 2009. Twenty years of postharvest biocontrol research: is it time for a new paradigma?. Postharvest Biology and Technology. 52(2): 137-145.

El-Otmani, M., Ait-Oubahou, A. and Zacarías, L. 2011. Citrus spp.: Orange, mandarin, tangerine, clementine, grapefruit, pomelo, lemon and lime. In: Postharvest biology and technology of tropical and subtropical fruits (pp. 437-516e). Woodhead Publishing.

Fathollahi, I., Farmani, J., Kasaai, M. and Hamishehkar, H. 2021. Some physical properties of Persian lime (Citrus latifolia) seeds and physicochemical properties of the seed oil as affected by solvent extraction and cold pressing methods. 
Journal of Food Measurement and Characterization. 15: 1169-1178.

FAO. 2019. Annual statistics. http://www.fao.

Guo, K., Li, Z., Tian, H., Du, X., Liu, Z., Huang, H., Wang, P., Ye, Z., Zhang, X. and Tu, L. 2020. Cytosolic ascorbate peroxidases plays a critical role in photosynthesis by modulating reactive oxygen species level in stomatal guard Cell. Frontiers in Plant Science. 11: 446.

Hernandez-Montiel, L., Ochoa, J., Troyo-Diéguez, E. and LarraldeCorona, C. 2010. Biocontrol of postharvest blue mold (Penicillium italicum Wehmer) on Mexican lime by marine and citrus Debaryomyces hansenii isolates. Postharvest Biology and Technology. 56(2): 181-187.

Jain, A., Chatterjee, A. and Das, S. 2020. Synergistic consortium of beneficial microorganisms in rice rhizosphere promotes host defense to blight-causing Xanthomonas oryzae pv. oryzae. Planta. 252(6): 1-25.

Jing, J., Zhang, H., Xue, Y. and Zeng, K. 2020. Effects of INA on postharvest blue and green molds and anthracnose decay in citrus fruit. Journal of Integrative Agriculture. 19(5): 13961406.

Kanashiro, A., Akiyama, D., Kupper, K. and Fill, T. 2020. Penicillium italicum: An underexplored postharvest pathogen. Frontiers in Microbiology. 11: 606852.

Kellerman, M., Joubert, J., Erasmus, A. and Fourie, P. 2016. The effect of temperature, exposure time and $\mathrm{pH}$ on imazalil residue loading and green mould control on citrus through dip application. Postharvest Biology and Technology. 121: 159-164.

Khedia, J., Dangariya, M., Nakum, A., Agarwal, P., Panda, A., Parida, A., Gangapur, D., Meena, R. and Agarwal, P. 2020. Sargassum seaweed extract enhances Macrophomina phaseolina resistance in tomato by regulating phytohormones and antioxidative activity. Journal of Applied Phycology. 32(6): 4373-4384.

Klein, A., Hüsselmann, L., Keyster, M. and Ludidi, N. 2018. Exogenous nitric oxide limits salt-induced oxidative damage in maize by altering superoxide dismutase activity. South African Journal of Botany. 115: 44-49.

Konsue, W., Dethoup, T. and Limtong, S. 2020. Biological control of fruit rot and anthracnose of postharvest mango by antagonistic yeasts from economic crops leaves. Microorganisms. 8(3): 317.

Leyva-Acuña, M., Quintana-Obregón, E., Soto-Landeros, F., Baez-Parra, K., Montes-Avila, J. y Angulo-Escalante, M. 2020. Actividad antifúngica de extractos metanólicos y alcaloides de Jatropha platyphylla contra Aspergillus parasiticus. Biotecnia. 22(3): 100-107.

Li, B., Xu, H., Wang, X., Wan, Y., Jiang, N., Qi, H. and Liu, X. 2020. Antioxidant and antihyperlipidemic activities of high sulfate content purified polysaccharide from Ulva pertusa. International Journal of Biological Macromolecules. 146: 756-762.

Moenne, A., Gómez, M., Laporte, D., Espinoza, D., Sáez, C. and González, A. 2020. Mechanisms of copper tolerance, accumulation, and detoxification in the marine macroalga Ulva compressa (Chlorophyta): 20 years of research. Plants. 9(6): 681.

Moussa, H., El Omari, B., Chefchaou, H., Tanghort, M., Mzabi, A., Chami, N. and Remmal, A. 2021. Action of thymol, carvacrol and eugenol on Penicillium and Geotrichum isolates resistant to commercial fungicides and causing postharvest citrus decay. Canadian Journal of Plant Pathology. 43(1): 26-34.

Mukherjee, A., Verma, J., Gaurav, A., Chouhan, G., Patel, J. and Hesham, A. 2020. Yeast a potential bio-agent: future for plant growth and postharvest disease management for sustainable agriculture. Applied Microbiology and Biotechnology. 104(4): 1497-1510.

Ochoa, J., Hernandez-Montiel, L., Latisnere-Barragan, H., León de la Luz, J. y Larralde-Corona, C. 2007. Aislamiento e identificación de hongos patógenos de naranja (Citrus sinensis L. Osbeck) cultivada en Baja California Sur, México. Ciencia y Tecnología Alimentaria. 5: 352-359.

Ons, L., Bylemans, D., Thevissen, K. and Cammue, B. 2020. Combining biocontrol agents with chemical fungicides for integrated plant fungal disease control. Microorganisms. 8(12): 1930.

Palmieri, D., Vitullo, D., De Curtis, F. and Lima, G. 2017. A microbial consortium in the rhizosphere as a new biocontrol approach against fusarium decline of chickpea. Plant and Soil. 412(12): 425-439.

Pandhal, J. and Noirel, J. 2014. Synthetic microbial ecosystems for biotechnology. Biotechnology Letters. 36: 1141-1151.

Panebianco, S., Vitale, A., Polizzi, G., Scala, F. and Cirivilleri, G. 2015. Enhanced control of postharvest citrus fruit decay by means of the combined use of compatible biocontrol agents. Biological Control. 84: 19-27.

Pankiewicz, R., Leska, B., Messyasz, B., Fabrowska, J., Soloducha, M. and Pikosz, M. 2016. First isolation of polysaccharides ulvans from the cell walls of freshwater algae. Algal Research. 19: 348-35.

Papoutsis, K., Mathioudakis, M., Hasperué, J. and Ziogas, V. 2019. Non-chemical treatments for preventing the postharvest fungal rotting of citrus caused by Penicillium digitatum (green mold) and Penicillium italicum (blue mold). Trends in Food Science and Technology. 86: 479-491.

Pérez-Nájera, V., Lugo-Cervantes, E., Gutiérrez-Lomelí, M. y DelToro-Sánchez, C. 2013. Extracción de compuestos fenólicos de la cáscara de lima (Citrus limetta Risso) y determinación de su actividad antioxidante. Biotecnia. 15(3): 18-22.

Qi, C., Lin, X., Li, S., Liu, L., Wang, Z., Li, Y., Bai, R., Xie, Q., Zhang, N., Ren, S., Zhao, B., Li, X., Fan, S. and Guo, Y. 2019. SoHSC70 positively regulates thermotolerance by alleviating cell membrane damage, reducing ROS accumulation, and improving activities of antioxidant enzymes. Plant Science. 283: 385-395.

Rivas-Garcia, T., Murillo-Amador, B., Nieto-Garibay, A., ChiquitoContreras, R., Rincon-Enriquez, G. and Hernandez-Montiel, L. 2018. Effect of ulvan on the biocontrol activity of Debaryomyces hansenii and Stenotrophomonas rhizophila against fruit rot of Cucumis melo L. Agronomy. 8(12): 273.

Sánchez-Espinosa, A., Villarruel-Ordaz, J. y Maldonado-Bonilla, L. 2021. Mycoparasitic antagonism of a Trichoderma harzianum strain isolated from banana plants in Oaxaca, Mexico. Biotecnia. 23(1): 127-134.

SADER, 2019. Estadísticas de cítricos, Superficie Cosechada, Sembrada y Producción. www.gob.mx

Solairaj, D., Legrand, N., Yang, Q. and Zhang, H. 2020. Isolation of pathogenic fungi causing postharvest decay in table grapes and in vivo biocontrol activity of selected yeasts against them. Physiological and Molecular Plant Pathology. 110: 101478. 
Spadaro, D., Ciavorella, A., Dianpeng, Z., Garibaldi, A. and Gullino, M. 2010. Effect of culture media and $\mathrm{pH}$ on the biomass production and biocontrol efficacy of a Metschnikowia pulcherrima strain to be used as a biofungicide for postharvest disease control. Canadian Journal of Microbiology. 56(2): 128-137.

Spadaro, D. and Droby, S. 2016. Development of biocontrol products for postharvest diseases of fruit: the importance of elucidating the mechanisms of action of yeast antagonists. Trends in Food Science and Technology. 47: 39-49.

Sui, Y., Wisniewski, M., Droby, S., Piombo, E., Wu, X. and Yue, J. 2020. Genome sequence, assembly, and characterization of the antagonistic yeast Candida oleophila used as a biocontrol agent against post-harvest diseases. Frontiers in Microbiology. 11: 295.

Taqarort, N., Echairi, A., Chaussod, R., Nouaim, R., Boubaker, H., Benaoumar, A. and Boudyach, E. 2008. Screening and identification of epiphytic yeasts with potential for biological control of green mold of citrus fruits. World Journal of Microbiology and Biotechnology. 24: 3031-3038.
Wassermann, B., Kusstatscher, P. and Berg, G. 2019. Microbiome response to hot water treatment and potential synergy with biological control on stored apples. Frontiers in Microbiology. 10: 2502.

Zhang, H., Zheng, X. and Yu, T. 2007. Biological control of postharvest diseases of peach with Cryptococcus laurentii. Food Control. 18(4): 287-291.

Zhang, X., Zong, Y., Li, Z., Yang, R., Li, Z., Bi, Y. and Prusky, D. 2020. Postharvest Pichia guilliermondii treatment promotes wound healing of apple fruits. Postharvest Biology and Technology. 167: 111228.

Zhimo, V. Y., Biasi, A., Kumar, A., Feygenberg, O., Salim, S., Vero, S., Wisniewski, M. and Droby, S. 2020. Yeasts and bacterial consortia from kefir grains are effective biocontrol agents of postharvest diseases of fruits. Microorganisms. 8(3): 428.

Zhu, J., Gao, J., Yang, C., Shang, X., Zhao, Z., Lawoe, R., Zhou, R., Sun, Y., Yin, X. and Liu, Y. 2020. Design, synthesis, and antifungal evaluation of neocryptolepine derivatives against phytopathogenic fungi. Journal of Agricultural and Food Chemistry. 68(8): 2306-2315. 